\title{
The Contribution of the Financial Sector in the Economic Growth of Pakistan: A Literature Review on Growth Theories and Indicators of Economic Growth
}

Amir Gulzar*

Adventist University of Lukanga, Democratic Republic of Congo, Central Africa

\begin{abstract}
This study is a literature review of the economic growth theories and its determinants especially in consideration with the financial sector. The emphasis in the paper is on the economic growth of Pakistan. In the end, a framework is purposed which can be tested first in Pakistan and then in any other economy. Many empirical and non-empirical studies have been done to come up with a perfect model of determinants of economic growth most of them take into consideration either the data that is bank-related or macro data. This study comes up with a framework that considers both financial sector data and other macro-economic data.
\end{abstract}

Keywords: Financial sector; Economic growth; Indicators of economic growth

\section{Introduction}

Banking has always been the backbone of economic growth in a country. It provides financial assistance to the private sector and governments. It is clear that countries with stable financial sector enjoy a quick economic growth than those with less stable and unorganized financial sector. A study by Valickova et al. concludes that the effect of the banking sector on economic growth in less developed countries is weaker, and it is decreasing worldwide after the 1980s [1]. A healthy banking sector is a prerequisite for sustainable economic growth. Hamza and Khan note that stable and high performance of banks means profitability and stability in the financial sector [2]. An increase of profitability of the banking sector means better performance by the banks which in other words, means more availability of capital for investment. According to Liang and Reichert [3], the more efficient the financial sector becomes, it is likely that country's scarce resources can be directed to their most productive use and with this the economic growth reaches to its full potentials.

The financial sector structure has become more important in the recent years. Banking sector plays an important role in collecting the funds from savers and channel them to those in need of investments (investors). Opoku-agyemang notes that banks are intermediaries between savers and investors [4]. Accounting to Javaid et al. the soundness of the financial system, especially the banking system, is a key part of the infrastructure for strong macroeconomic and monetary policy performance at the national level [5]. According to Claessens and Feijen [6], the financial sector through its banking system enables bigger investments and more productive allocation of capital, which lead to higher income growth. Banking sector does play a vital role in the economic growth in an economy.

Due to the regulatory structure and external factors, the banking sector has undergone lots of changes in the past few decades. Increase in supply through new forms of financing, the introduction of new information and communication technologies, an increase in competition and access to national and international financial markets have changed the way banking works. As Nouaili et al. [7] notes that amid these restructuring of the banking sector they have remained the major actors of economic growth. Understanding the behavior and the impact of performance of banks as well as its consequences on the national economy is of crucial importance in the today's world of information and communication.

The relationship between banking sector performance and economic growth is under controversial debate. According to AlKhulaifi and Al-Sulaiti [8], the role of the financial sector on the economic growth cannot be the same in each economy it differs due to the difference in economic environment and banking policies in a country. However, some analysts insist that financial institutions are a technique available for a country to promote its economic growth. On the other hand, some consider banks to be an indispensable part of economic growth in a country. Many researchers such as Aurangzeb, Hamza and Khan, Valickova et al., Ali, in their empirical studies have found a positive impact of the banking sector on economic growth of an economy $[1,2,9,10]$. On the other hand, some others have shown a negative, insignificant or no impact of the banking sector on economic growth [7,11-13].

A meta-analysis study done by Valickova et al. [1] studied 1334 pieces of research on the relationship between finance and economic growth. In their 638 (about 48\%) concluded statistically positive significant relationship, $446(33 \%)$ are statistically positive but insignificant, whereas, $128(10 \%)$ are negative and significant and $122(9 \%)$ is negative but insignificant. These findings show that only half of the studies found a statistically positive significant relationship between the banking sector and economic growth. The authors further argue that these positive significant results may be due to publication selection bias.

Pakistan has a well-established banking sector. Its financial sector is dominated by the commercial banks. According to Hamza

*Corresponding author: Amir Gulzar, PhD, Adventist University of Lukanga Democratic Republic of Congo, Central Africa, Tel: +243998605015; E-mail: amirgulzar2000@hotmail.com

Received August 24, 2018; Accepted September 26, 2018; Published September 30, 2018

Citation: Gulzar A (2018) The Contribution of the Financial Sector in the Economic Growth of Pakistan: A Literature Review on Growth Theories and Indicators of Economic Growth. J Bus Fin Aff 7: 352. doi: 10.4172/2167-0234.1000352

Copyright: (c) 2018 Gulzar A. This is an open-access article distributed under the terms of the Creative Commons Attribution License, which permits unrestricted use, distribution, and reproduction in any medium, provided the original author and source are credited. 
and Khan [2] Pakistani banks are leading institutions and banking sector is growing rapidly for the last two decades. The banking sector operates in a very competitive environment. Every bank wishes to have a maximum number of the client who deposits money with the bank and in return lends this money to borrowers hence, increasing its profitability and performance. Pakistani banks as any other banks in developing countries provide a wide range of services to its clients such as online banking, mobile banking, facilities to pay bills online or through mobile, making purchases or other payments through online or mobile banking etc. The purpose of this research is to identify the relationship of the banking sector with economic growth in Pakistan.

Sustainable economic growth is the utmost desire of every economy. Economic growth is the harmonious welfare of human beings in a society. Claessens and Feijen [6] argues that human capital, labor, technology, and capital are the main determinants of economic growth. They further explain that human capital is decomposed into two parts: education and health, the effects of education and health on economic growth are corroborated by many micro and countrylevel studies. Growth in the financial sector explains a good part of GDP per capita across countries. "Growth in financial sector ranks second among variables that are known for their substantial impact on GDP per capita" [6]. according to Ali [10], financial sectors is one of the prominent contributors to economic growth. Therefore, one can conclude that the strengthening of the financial sector is crucial for economic growth in a country.

\section{Definition of Terms}

1. Economic Growth-the capacity of an economy to produce goods and services, compared with one period to another. In other words, it means the overall increase in the productivity of an economy, which means the labor force has become more productive than before.

2. Gross Domestic Product (GDP)-a monetary value of the final goods and services produces during a given period.

3. Deposits is the placement of funds with a bank or other financial institutions to be withdrawn at any time. The depositor agrees by keeping his funds in the bank that they can be used by the bank for further investments.

4. Advances-an amount of money loaned by the bank to the borrower at an interest usually by holding back a collateral.

5. Interest earnings-the amount of money earned by banks as results of loaning activity which is the core business of banks.

6. Profitability-it is the ability of a business to produce surplus after paying all the expenses. In terms of banks, this surplus is produced from interest on the loans and other investments made by the banks.

7. Investments-in banking terms it is the number of money banks has loans to clients for the purpose of investing in other business. Sound investment activities are key to economic development.

8. Financial Development Index (FDI)-measure and analysis of the factors enabling development of the financial system in an economy.

9. Domestic saving as a percentage of GDP-it is the GDP minus the consumption. This saved money is either kept in the public or invested back in the business. There are two types of saving the public saving and domestic saving. The public saving is by banks, on the other hand, the domestic saving is by the households which are invested back into the business through banks.

10. The ratio of GDP business investment-the part of money invested back into the business by the government or public. The gross domestic formation is defined as the sum of fixed assets formation and changes in inventories.

11. Private sector credit to GDP-financial resources provided to the private sector by financial corporations, through loans, purchase of securities, and trade credits or other accounts receivables.

\section{Theories of Economic Growth}

The problems of economic growth are complex and multidimensional, this has led to a number of economic growth theories. The word theory is used in different ways. Some people refer to the theory as saying things are impractical, something that is true in theory and cannot be applied in practice. Whereas, in economic terms, a theory can be said as the interrelationship of economic variables. Therefore, the purpose of the theory is to explain the causal relationship between these related variables. Kuznets et al. [14] gives two types of theories inductive and deductive. The inductive theory is data-driven; what does the data say, and a theory or story is formed to explain the data. The economists prefer deductive theories that are more in line with a thought experiment. According to Shareia [15] economic growth theories help developing countries in matters of development of policies that improve a nation's position economically, socially and institutionally. Theories of economic growth came into existence in the 20th century when the decolonization occurred for the underdeveloped counties.

Over the past few decades, three main theoretical approaches to economic growth have dominated the field of economic development. Vaitsos [16] explains these approaches as follows: First, formal aggregate economic growth modeling, as dominated for decades by neoclassical economic formulations under very limiting basic assumptions, related increases of outputs. Second, the thrust for theoretical interest in evolutionary economic theorizing, with this approach overall economic performances, depending on the prevailing variations beneath the aggregate level and that in a market economy, changes take place in the context of continuous disequilibrium, evolutionary theorizing is often based on an analysis of micro and macroeconomic phenomena. Finally, a more holistic approach of economic historians which focus on a wider spectrum (such as capital accumulations, education attainment, political evolutions and broader social phenomena) of phenomena that might otherwise escape adequate explanations, especially in formal growth theorizing.

Most of the economic growth theories came into existence in the 1950s. According to Kuznets et al. [14] the story of economic growth starts with farmers who specialize in certain types of agriculture products. Some farmers are good at raising certain crops while others are better at livestock. This specialization also leads to higher levels of productivity and as a result, income increases thus, the growth process begins. In the 1980s three different thoughts changed the way economic growth theories are looked at. First, the stability of the neoclassical model is based on the assumption of constant returns to scale in production technologies whereas, we know in the real world that, economies of scale exits. Second, we know that economic growth is geared by the new ideas, products, and innovations whereas, in a neoclassic model no mechanism explains why innovation occurs. Third, beginning in the mid-1970s the income patterns have reversed which boosted the economic development. 
Over the past few decades, there have been economic uncertainties which means no single formula for economic growth would work or would not work. This has brought the changes in the application of economic theory some strategies turn out to be successful in applying the same theory whereas, others have not been so successful [17]. The changes occur due to five reasons as given by Adelman [18]. First, Learning, as the new empirical and theoretical knowledgebase enlarges, new propositions, the new evidence about the real-world success or failures occur. Secondly, changes in ideology, as different power-elites ascend and wane, their ideologies ascend and wane with them replaced by the new ideologies thus, bringing a change in the existing theories. Thirdly, changes in the international environment, when major technological innovations, such as the industrial or the communications revolution, or major global institutional transforms occur these results into new dynamics of economic growth thus, affecting both the policy and theory. Fourthly, changes in domestic institutions, constraints, and aspirations, their dynamics of development themselves fundamentally restructure institutions and some constraints while tightening others, this brings new aspirations. Finally, the culture of the discipline, which serves to structure the art of discourse and manner of argumentation in the discipline.

The concept of development is defined differently in every theory. For example, modernization theory stresses the cultural features of each society, such as political, religion and culture. On the other hand, world system theory and globalization seek to evaluate the external relations and to define different points in the development of countries [15]. According to Crafts [19] growth economists have used growth regressions in attempts to discriminate between competing claims in growth theory, development economists have used them to project future growth, to evaluate growth performance across countries, to bolster generalizations relating to the role of factor accumulation and initial backwardness in growth.

The controversies have existed between two main thoughts of economic growth the neo-classical approach and endogenous growth models. This has certainly contributed to the revitalization of economic growth theory. According to Thiel [20] from the neoclassical point of view, economic growth is entirely driven by the accumulation of input factors and technical progress, with the potential role of finance by providing capital. On the other hand, endogenous growth approaches stress the role of entrepreneurship and innovation, which allows finance to direct incentives to research and innovations. Looking at the above viewpoints some economists would doubt for a very high contribution of finance in economic development. The importance to the question of finance is explained through two questions. First, is finance development a pre-condition for economic growth or does the financial sector development in parallel with overall economic growth? Second, do differences in financial development only account for differences in the early stages of economic growth or do they also matter for industrial economies.

\section{Economic Growth Theories}

\section{Neoclassical theory}

This theory contends that a particular set of intuitions in an economy does not matter. According to Hoff and Stiglitz, [17] this theory rests on three different points (a) outcomes are determined by fundamental forces (reflecting resources, preferences, and technology) (b) these forces lead to Pareto-efficient outcomes, and (c) institutions do not even influence the choice of the equilibrium. Neoclassical economics argue that neither institutions nor wealth distribution mattered for efficiency; productive resources always gravitated through market exchanges into the hands of the persons who valued them the most [17]. The modeling techniques resolve for the impersonal outcomes that would emerge from an impersonal setting with the market for all goods, all periods, and all risks where people make trades and the history does not matter. According to Dang and Pheng [21], the argument of the neoclassical theory states that underdevelopment is not the result of predatory activities rather it the result of domestic issues arising from heavy state intervention such as poor resources allocation, government-induced price distortions, and corruption.

Another strand of neoclassical growth theory originated from Harrod-Domar and Solow models where Solow neoclassical growth model stresses the importance of three factors of output growth: increase in labor quantity and quality, increases in capital and improvement in technology $[21,22]$. In his article Blanchard et al., explains in detail the Solow Model of growth, according to them, the economic growth goes hand in hand with saving and population growth. Solow's model predicts that higher the rate of saving the richer the country will be and the higher the rate of population growth the poorer the country will be. Examining recently available data they find that savings and population growth affect income in the direction that Solow predicted. Thus, proving that neoclassical theory supported by Solow is still valid and is confirmed by the empirical data.

In the existing Solow model, Mankiw et al. [23] included another dimension which is an accumulation of human as well a human capital. They tested the new model empirically and found that human capital is in fact correlated with the saving and population growth. The human capital accumulation lowers the estimated effects of saving and population growth to roughly the values predicted by the Solow model. Ranis [22] affirms that Solow provided the most important transitional mechanisms in the realm of both neoclassic theory and policy, his contribution was to emphasize, the importance of changing economic environment through the technological innovations. He provided a new point of departure for the neo-classical growth theory.

\section{Endogenous growth theory}

This model notes that technological changes over time have not been equally transmitted in developing counties. The new growth theorists link technological growth to the product knowledge. This theory emphasizes that economic growth results from the use of knowledge rather than labor and capital [21,24]. This theory argues that the higher rate of returns as expected in the Solow model is greatly eroded by lower levels of complementary investment in human capital (knowledge), infrastructure, or research and development whereas, knowledge is different from other economic goods because of its possibility to grow boundlessly. According to Masoud in the new growth paradigm the focus shift from production of wealth through the human capital to the knowledge acquisition over time [25]. All theoretical and empirical studies have emphasized on the role played by the financial market development in the overall development of the economy however, the new growth theory has re-emphasized the number of fundamental issues concerning the interdiction of technical progress, economies of scale and formation of physical convergence of countries.

\section{Theory of coordination failure}

This theory argues that the market may fail to achieve coordination among complementary activities. When the return of one investment depends on the development of another investment and that other investment somehow fails it will automatically fail the principal 
investment. According to Dang and Pheng [21] two scenarios exits, one is all investors as a whole are better off when all investment to be achieved at the same time. On the other hand, it is not good for one investor to take the same actions when he knows that others will not do the same. This theory initially came onto the scene in the 1990s but it existed even before that where different industries fail to coordinate their activities.

\section{Theories of development}

Apart from the theories of economic growth there also theories devised for the overall development. Economic growth is a sub-field of development. The objective of developmental studies is to provide support for economic development. The field is concerned with devising tools and approaches to the economic, social and institutional aspects of developing countries in order to achieve improvements in the standards of living [15]. Theories of growth were motivated in the 20th century when the decolonization occurred and the disparity between Europeans nations and the rest of the world became obvious. There are four major types of growth theories:

1. Modernization theory-this theory is defined as the systemic process to move underdeveloped countries to a more sophisticated level of development. The focus of modernization theory is culture change directed at institutional structures in non-industrialized countries [15].

2. Dependency theory-this theory has been presented to improve modernization theory. The focus of this theory is the totality of society and social system periphery, which highlights the differences by focusing on regions and structural conditions in different nations states. It explains the relationship between dominant and underdeveloped nations [15].

3. World Systems theory-this theory argues that international trade specialization and transfer of resources from less developed counties to developed countries permit development in less developed counties by making them rely on core countries and by encouraging peripheralization $[15,26]$. This theory of growth deals with different forms of capitalism worldwide.

4. Globalization theory-the focus of this theory is communications and international ties, with these this directed at cultural and economic factors in communication systems. It explains inequality by identifying cultural and economic factors in global connections [15].

\section{Economic growth}

The goal of economic growth is to create a wealth of a nation. The need to stimulate economic growth is a topic of importance in an advanced, emerging and less developed economies. With the increase in population many less developed economies are facing the challenge of improving economic growth. As Liang and Reichert [3] note that with population growth in less developed economies and the changing demographics and widening income disparities in many of the most advanced economies, the issue of economic growth has taken on increased importance. Economic growth is defined as the process by which the supply of goods and services is increasing while improving the quality of life [27]. According to Azam and Khattak [28], economic growth is the automatic birthright for an economy, therefore, for an economy to grow, it has to create the right conditions for growth.

Economic growth is measured by the increase in Gross National Product (GNP) and Gross Domestic Product (GDP). The world bank now replaces GNP per capita with Gross National Income (GNI) per capita to compare wealth among countries [21]. According to Hamza and Khan [2], the most important indicator for decision makers and governments use to make decisions and policies for a country. It tells about the overall health of the economy in a country. GDP is defined as the sum of all goods and services produced in a country over time, without double counting products used in other outputs. This indicator measures that well-being and development based on material wealth Mo [29] identifies four variables for determining economic growth these are a share of investment in GDP, the rate of population growth, and initial level of real GDP per capita, and proxy for human capital. His first two variables belong to the growth component and last two belongs to the development component.

According to the Federal Bureau of Statistics, Pakistan the economic growth has a steady increase over the years it was $1.2 \%$ in $1971,7.3 \%$ in 1980 , and $8.4 \%$ in 2005 . All through the years agriculture have been the leading sector in the economic growth of Pakistan unfortunately since 2005 its growth has been fragile, it grows by $2.05 \%$ as against $6.7 \%$ of the last years. The slow growth has been due to the changing weather condition over the past few years and lack of government support in the agriculture sector [28]

\section{Financial sector and economic growth relationship}

There is no doubt that the financial sector has a positive relation to economic growth. Claessens and Feijen [6] argues that there exists a positive relationship between the financial sector and economic growth even when other important factors are taken into consideration. There is a strong evidence that good financial conditions cause development. As an example, in 1970, Zaire was among the developing countries with a very high credit extended to GDP, if it would have continued its economic growth would have been much faster than that of today. "In fact, over the period 1970-80, Zaire would have boosted its GDP per capita by 9 percent above its actual level if it would have financially more developed" [6].

The growth in the financial sector and economic growth always go hand in hand. The argument of what comes before is still under debate, but one thing is certain both works together for the development of people. Increase in economic growth leads to higher income and education level which, therefore, in turn, generate greater sophisticated financial risk management services. Claessens and Feijen, Liang and Reichert $[3,6]$ argue that economic growth increases demand for more sophisticated and risk management related financial services. On the other hand, the banking sector provides financial capital to the capital markets which in return creates jobs resulting into economic development. There have been several studies such as Ullah et al. [30], Akbar et al. [31], Azam et al. [28] done in Pakistan that presented a positive relationship between economic growth and foreign direct investment.

\section{Determinants of economic growth}

Economic growth is considered to be harmonious growth in a country. Several indicators are studied to determine the rate of economic growth. Several theories and models have been devised for the determination of economic growth in a country some of them includes neoclassical and endogenous growth theories, the linear stages of growth models, structural change models, international dependence models, New classical counter-revolution models, the theory of coordination failure [21]. Some of these theories will be explained in the section above. One major indicator of economic growth is GDP which is affected by several factors. Over the past few decades, the 
determinants of economic growth have taken an increasing attention in both theoretical and applied research. Yet the process underlying economic performance is inadequately conceptualized and poorly understood. Despite the lack of a unifying theory, there are several partial theories that discuss the role of various factors in determining economic growth [24].

Petrakos and Arvanitidis [24] in their empirical study identified 20 determinant of economic growth such as: high quality of human capital, high technology, stable political environment, high degree of openness, secure formal institutions, good infrastructure, capacity for adjustment, specialization in knowledge and capital incentive sectors, significant foreign direct investment, free market economy, rich natural resources, robust macroeconomic management, low levels of public bureaucracy, favorable demographic conditions, favorable geography, strong informal institutions, significant urban agglomerations, capacity for collective action, and random factors. According to Ullah et al. [30] among the many indicators proposed for the determinants of economic growth the neoclassical model highlights that saving and investment ratio is an important determinate of short-run economic growth and technological progress in the long run. Here is the description of some determinates of economic growth:

1. Investment ratio - this is one of the financial indicators of GDP. The ratio of investment is driven by savings in a country. According to Robert [32], a higher saving rate raises the steady-state level of output per effective worker and thereby raises the growth rate for a given value of GDP. The banking sector is one of those channels through which investment is produced. This is among the most important determinant identified by both neoclassic and endogenous growth models. However, in the neoclassical model investment has an impact on the transitional period, while the endogenous growth models argue for more permanent effects [24].

2. Gross Domestic Product - this indicator is used to measure the economic health of a country and also gauges a country's standard of living. It is the monetary value of all the finished goods and services, produced within a country's borders in a specified time and is calculated on annual basis [31].

3. Trade policy-this factor determine why some are rich and others are poor. Many developing countries are adopting the closed type of model which discourages trade and investment in the country. The trade policy can be addressed in either term of trade outcome that is the share of trade in GDP and changes therein or in terms of instruments that affect trade.

4. Economic openness-the more the economies look outward the richer they become. Openness has its critics where some economist believes that restricting all imports would allow foreign firms to take advantage of the methods of lower cost and could seriously affect the domestic industry. There no effective method that can help measure openness statistically [33].

5. Education-it is believed that education brings about a higher income for individuals and societies. Education helps make investment more productive and leads to higher growth. Microdata from around the world yield very robust results for the positive effects of education: each extra year of education adds about 12 percent to a person's lifetime income, although for macro data there is no significant coefficient for education [34].

6. Institutions-the theory that institutions play an important role in growth rests on two arguments. First, economic freedom reduces uncertainty and enhances entrepreneurship, among other things, this leads to greater efficiency and higher growth. Second, political freedoms lead to better decisions due to check and balance [34].

7. Foreign Direct Investment-this is an important indicator that shows the confidence of foreign investors in the economic, political and security stability of a country. An empirical study by Rahman and Salahuddin [31] considering empirical data in Pakistan from 1971-2006 shows a positive association between foreign direct investment and economic growth. This indicates that foreign direct investment stimulates economic activity and improves that quality of human capital spillover effects. Foreign direct investment promotes economic growth through improved technology transferee, efficiency, improvement in the quality of production factors and enhances production (Figure 1) [35].

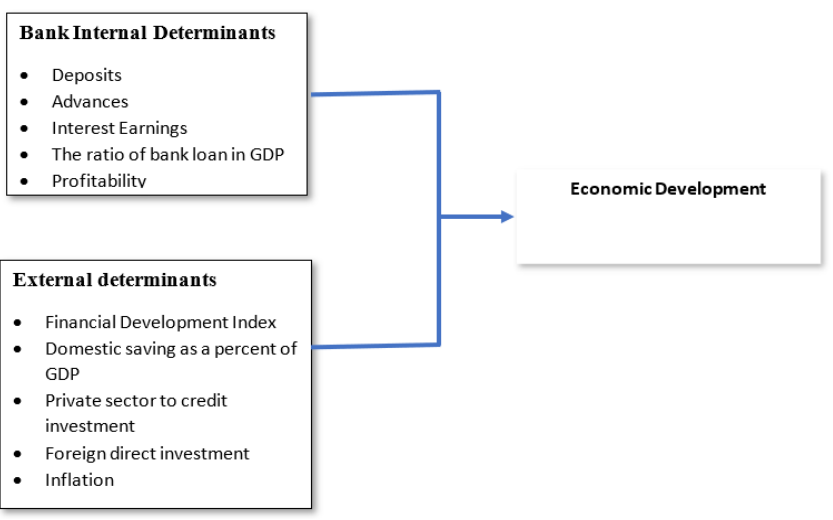

Figure 1: Proposed theoretical framework.

\section{Conclusion}

Over the years there have been numerous studies done to come up with the best predictive model for indicators of economic growth in a country. Different methodologies have been used to come up with different models. However, most of these studies present divergent models. This study is a literature review on the financial contribution to the economic growth of a country. Over the past few years, financial institutions have become an integral part of the economic development. It is through the financial sector that capital is provided to the business sector which eventually contributes to the economic growth of a country. Many studies as indicated in the above discussion have argued that financial sector empowerment, political and security stability are the most important ingredients of economic development.

Several theories have been given over the past decades in the prediction of economic development. No one theory can be said to have the perfect solution for the predictive determinants of economic development. However, different theories can be used in different situation to come up with determinants. The most used theories are neoclassical theories which argue that growth in an economy is determined by the marketplace in simple terms, if the marketplace can offer lots of exchanges there will be growth otherwise it may not be possible. On the other hand, Endogenous growth Theory adds to the existing neoclassic theory arguing that economic growth is also influenced by the technological transformations. Most of the studies take into consideration either the internal determinant of the banking sector or the only the external determinants to predict the economic development. This study proposes a framework that is based on both micro and macro determinants that can predict the economic growth 
Citation: Gulzar A (2018) The Contribution of the Financial Sector in the Economic Growth of Pakistan: A Literature Review on Growth Theories and Indicators of Economic Growth. J Bus Fin Aff 7: 352. doi: 10.4172/2167-0234.1000352

in an economy. This framework can be tested with empirical data first in Pakistan and then in other economies.

\section{References}

1. Valickova P, Havranek T, Horvath R (2013) Financial development and economic growth: A meta-analysis. Institute for East and Southeast European Studies.

2. Hamza SM, Khan EA (2014) Effect of banking sector performance in economic growth: A Case study of Pakistan. J Appl Environ Biol Sci 4: 444-449.

3. Liang HY, Reichert A (2006) The Relationship between economic growth and banking sector development. Banks and Bank System 1: 19-35.

4. Opoku-agyemang DA (2015) Factors influencing the profitability of domestic and foreign banks in Ghana. AARHUS University, Ghana.

5. Javaid S, Anwar J, Zaman K, Gafoor A (2011) Determinants of bank profitability in Pakistan: An Internal factor analysis. Med J Soc Sci 2: 59-78.

6. Claessens S, Feijen E (2006) Financial sector development and the millennium development goals. World Bank, World Bank, USA

7. Nouaili M, Abaoub E, Ochi A (2015) The determinants of banking performance in front of financial changes: Case of trade banks in Tunisia. Int J Econ Financ Issues 5: 410-417.

8. Al-Khulaifi A, Al-Sulaiti K, Al-Khatib F (1999) Banking performance and economic growth in Qatar: An Empirical Investigation. J Adm Sci Econ 10: 5-27.

9. Aurangzeb (2012) Contributions of the banking sector in economic growth: A Case of Pakistan. Econ Financ Rev 2: 45-54.

10. Ali R (2014) The role of bank-based finance in economic growth of Pakistan Middle-East Journal of Scientific Research 22: 82-90.

11. Akakabota EE, Mmadu BA (2015) Financial sector reforms and economic growth in Nigeria. Int J Econ Commer Manag III: 150-171.

12. Akmal M, Saleem M (2008) Technical efficiency of the banking sector in Pakistan. SBP Research Bulletin 4: 61-80.

13. Lucas RE (1988) On the mechanics of economic development. J Monet Econ 22: $3-42$.

14. Kuznets S, Rostow W, Nobel T, Solow R (1987) Economic growth theory: A brief history. Community Economic Development.

15. Shareia BF (2015) Theories of development. Inter J Language and Linguistics 2: $78-90$.

16. Vaitsos CV (2003) Growth theories revisited: Enduring questions with changing answers. Maastricht, Netherlands.
17. Hoff K, Stiglitz JE (2001) Modern economic theory and development. Front Dev Econ pp: 389-459.

18. Adelman I (1999) Fallacies in development theory and their Implications for policy.

19. Crafts NFR (2000) Development history. London school of economics, London.

20. Thiel M (2001) Finance and economic growth - A review of theory and the available evidence.

21. Dang L, Pheng M (2015) Infrastructure investments in developing economies. Int J Bus Manag 2: 11-27.

22. Ranis G (2004) The Evolution of development thinking: Theory and policy. Yale University, New Haven, CT.

23. Mankiw GN, Romer D, Weil DN (1992) A contribution to the empirics of economic growth. Q J Econ 107: 407-437.

24. Petrakos PG, Arvanitidis $P$ (2008) Determinants of economic growth. Economic Alternatives 1: 11-30.

25. Masoud N (2014) A contribution to the theory of economic growth: Old and New. J Econ Int Financ 6: 47-61.

26. Szymaniski A (1984) Socialist states in the world-system. Beverly Hills: Sage Publications.

27. Ashan K (2012) Role of commercial banks in economic development.

28. Azam M, Naeem Ur Rahman K (2009) Empirical analysis of the determinants of economic growth in Pakistan, 1971-2005. Sarhad J Agric 25: 307-312.

29. Mo PH (2001) Corruption and Economic Growth. J Comp Econ 29: 66-79.

30. Ullah S, Khan S, Shah M, Khan SA (2013) Assessment of key determinants for economic growth in Pakistan (1980-2009). World Appl Sci J 26: 1357-1363.

31. Akbar A, Imdadullah M, Aman Ullah M, Aslam M (2011) Determinants of Economic Growth in Asian Countries: A Panel Data Perspective. Pak J Soc Sci 31: 145-157.

32. Robert JB (1996) Determinants of economic growth: A cross-country empirical study. Natl Bur Econ Res, pp: 1-118.

33. Rahman MM, Salahuddin M (2010) The determinants of economic growth in Pakistan: Does stock market development play a major role? Economic Issues 15: 69-86.

34. Eliot TS, Gidding L (2008) Devaluing to prosperity: In Determinants of Economic Growth. Peterson Institute for International Economics, pp: 11-32.

35. Shahbaz M, Ahmad K, Chaudhary AR (2008) Economic Growth and Its Determinants in Pakistan. The Pakistan Development Review 47: 471-486. 